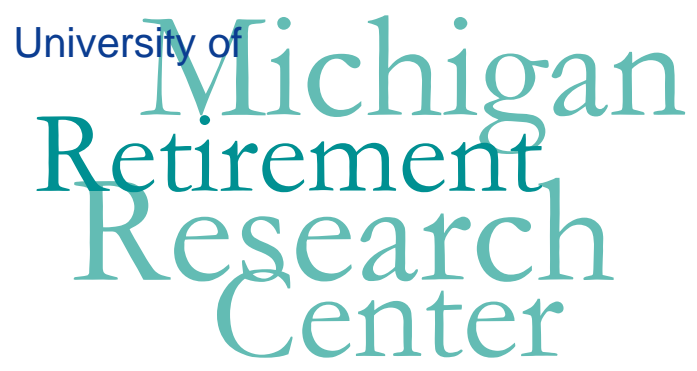

Working Paper WP 2009-210

\title{
Social Security Literacy and Retirement Well-Being
}

Hugo Benítez-Silva, Berna Demiralp and Zhen Liu

\begin{tabular}{|l|l|l|l|l|l}
\hline $\mathrm{M}$ & $\mathrm{R}$ \\
\hline $\mathrm{R}$ & $\mathrm{C}$ & Project \#: UM09-11 \\
\hline
\end{tabular} 



\title{
Social Security Literacy and Retirement Well-Being
}

\author{
Hugo Benítez-Silva \\ SUNY-Stony Brook \\ Berna Demiralp \\ Old Dominion University \\ Zhen Liu \\ University at Buffalo
}

September 2009

\author{
Michigan Retirement Research Center \\ University of Michigan \\ P.O. Box 1248 \\ Ann Arbor, MI 48104 \\ http://www.mrrc.isr.umich.edu/ \\ (734) 615-0422
}

\section{Acknowledgements}

This work was supported by a grant from the Social Security Administration through the Michigan Retirement Research Center (Grant \# 10-M-98362-5-01). The findings and conclusions expressed are solely those of the author and do not represent the views of the Social Security Administration, any agency of the Federal government, or the Michigan Retirement Research Center.

\section{Regents of the University of Michigan}

Julia Donovan Darrow, Ann Arbor; Laurence B. Deitch, Bingham Farms; Denise Ilitch, Bingham Farms; Olivia P. Maynard, Goodrich; Andrea Fischer Newman, Ann Arbor; Andrew C. Richner, Grosse Pointe Park; S. Martin Taylor, Gross Pointe Farms; Katherine E. White, Ann Arbor; Mary Sue Coleman, ex officio 


\title{
Social Security Literacy and Retirement Well-Being
}

\begin{abstract}
We build upon the growing literature on financial literacy, which studies the prevalence of lack of knowledge about various financial issues, and analyze how much people know about the Social Security rules using a small pilot survey conducted in 2007, and a follow-up and extended survey funded by MRRC conducted in December of 2008. We then assess the consequences of the apparent prevalence of lack of information by individuals about the rules governing the Social Security system using a realistic and empirically-based life-cycle model of retirement behavior under uncertainty. We investigate the individual's retirement and savings decisions under incomplete information and unawareness, in which a portion of the population does not know some or all of the rules of the system. We compare the outcomes in these cases to the outcome under full information, computing the welfare gain resulting from the acquisition of information regarding the Social Security system. Our analysis can illuminate the need for policies that foster knowledge of the system, which can improve welfare, and can result in better policy outcomes.
\end{abstract}

\section{Authors’ Acknowledgements}

We gratefully acknowledge the financial support of the V.P. for Research at SUNY-Stony Brook through a Seed Grant which allowed us to start this project. The U.S. Social Security Administration has funded this project through grant UM09-11 at the MRRC, its support in this, and other related projects, has made this research a reality. The findings and conclusions expressed are solely those of the authors and do not represent the view of SSA, any agency of the Federal Government or the MRRC. The hard work of the administrators and interviewers at the Center for Survey Research at Stony Brook made it all this possible and we are very thankful to all of them. The key role played from the very beginning by Linda Pfeiffer at the Survey Center deserves special mentioning. Interestingly, Linda retired shortly after finishing helping us on our project. She claims this was unrelated to the project and its results. Anna Nesterenko provided superb research assistance. Any remaining errors are our sole responsibility. 


\section{Introduction and Motivation}

A large body of literature in economics has tried to explain the relationship between social insurance, labor supply, savings and consumption behavior of individuals. An increasingly influential branch of this literature tries to accomplish this by solving complex models of rational behavior. A critical assumption of these models is that people know the set of rules of the Social Security system. In this paper we first investigate how much people know about some of the basic rules of the Social Security system, and then present a life-cycle model that incorporates imperfect information, and study the consequences on retirement decisions, and ultimately on welfare.

We believe our research is crucial from a policy perspective because the incentives generated by the Social Security rules are dependent on people's understanding of these rules. If individuals do not know the rules of the system, or do not understand the implications of the rules on the value of their benefits, models that assume perfect information of the Social Security system would not yield accurate measures of the incentives created by the social insurance system.

We first study people's knowledge of the Social Security system by analyzing data from two surveys funded by a Seed Grant from Stony Brook’s Center for Survey Research and MRRC. The first survey was on the field in August of 2007, collected information on 500 individuals about their knowledge of some of the basic Social Security rules and how that knowledge was acquired. The follow-up was in the field in December of 2008, and we collected 507 observations. The follow-up part of the new survey allows us to test whether the respondents have improved in their knowledge of the system, and help us when modeling the information problem faced by individuals. Second, we provide a measure of the cost brought about by Americans' lack of information on the Social Security system's rules. To that end, we present a framework in which we can compute the individuals' welfare gain from acquiring information regarding the Social Security system, by solving and simulating a life-cycle model of retirement behavior under different informational assumptions.

Third, we discuss possible strategies that might increase individuals' awareness of the rules of the system, and evaluate which strategies would lead to more welfareimproving outcomes. 


\section{Methodology, Results, and Policy Implications}

The surveys we conducted included about 20 questions on respondents' knowledge of several rules that affect their Social Security benefits, such as the age of early and normal retirement, and the reduction factors with respect to the normal retirement, how they obtained their information, and their level of financial literacy with respect to calculations involving social security benefits, among others. The surveys were not limited to an older subpopulation, so we can assess people's knowledge of Social Security over an entire age profile. The surveys also included a standard battery of socio-economic, and demographic questions, as well as health and longevity expectations questions.

We find that there is significant variation in people's knowledge of Social Security rules, and that this knowledge varies by the year of the survey. For example, only $42 \%$ percent of the respondents interviewed in 2007 correctly answered the question "What is the youngest age at which an eligible worker can apply for his or her own Social Security retirement benefits?” but this percentage goes above 54\% in 2008, and almost to $56 \%$ among those re-interviewed in that year. We observe in this case this 2008 effect, which we interpret as suggesting that in an election year individuals are more informed about policy issues. The percentage of individuals answering correctly varies considerably by age, and in 2008 varies from around 20\% among those 18 to 34, to around $72 \%$ for those 55 to 64 . The variation with respect to income and education is considerably lower.

A much lower percentage, 22.8\%, gave the correct answer in 2007 to "What is the maximum age at which you can claim Social Security retirement benefits so that Social Security will adjust your benefits upward?" and the percentage is almost identical to the new respondents of 2008, however, it goes up to $45 \%$ among those re-interviewed.

The latter pattern appears throughout the survey, for example regarding the minimum number of years necessary to be eligible to receive benefits, or the incidence of the earnings test, showing a large increase in knowledge among the re-interviewed sample, which we interpret as implying considerable promise of policy recommendations the objectives of which is to encourage individuals to go and find out information which could be relevant to them. 
The second step in our methodology is to compute the cost that an individual incurs due to his/her lack of information on Social Security rules by comparing his/her welfare under full information to the welfare under imperfect information. In the benchmark model, individuals choose how much to consume and save, how much to work and when to retire, and when to claim benefits from Social Security under the assumption that they have perfect knowledge of all the retirement incentives.

We then present characterizations of partial information regarding Social Security rules. A key characterization we explore, which is an extreme case of unawareness, is when individuals do not know anything about the details of the system, and they decide when to claim Social Security benefits based on what they observe others to be doing.

The final step of our research discusses policy alternatives aimed at increasing the public's knowledge of the Social Security system. The policies that we consider include customizing the Social Security statement highlighting different messages according to the individual's characteristics, such as age, family situation, or earnings. For example, young individuals might receive highlighted messages regarding the features of the system on which they lack information based on our findings from the surveys, while older individuals might receive more detailed information about the consequences of claiming benefits and continue working. We believe that Social Security can exploit the knowledge heterogeneity we find to reach the population with more targeted messages. 


\section{Social Security Literacy and Retirement Well-Being 1. Introduction and Motivation}

For decades a large body of literature in economics has tried to explain the relationship between social insurance, labor supply, savings and consumption behavior of individuals. An increasingly influential branch of this literature tries to accomplish this by solving complex models of rational behavior. A critical assumption of these models is that people know and understand the complex set of rules of the Social Security system. In this paper we first investigate in detail how much people know about some of the most basic rules of the Social Security system, and then modify the standard life-cycle model to incorporate imperfect information, and study the consequences on retirement, savings decisions, and ultimately on welfare.

We believe that investigating people's knowledge of the Social Security rules, and the role of this knowledge on retirement and savings outcomes, is crucial from a policy perspective because the incentives generated by the Social Security rules are dependent on people's understanding of these rules. ${ }^{1}$ If individuals do not know the rules of the Social Security system, or do not understand the implications of the rules on the value of their benefits, models that assume perfect information of the Social Security system would not yield accurate measures of the incentives created by the social insurance system.

We investigate how much people know about the Social Security rules, how they incorporate this knowledge in their retirement and savings decisions, the extent to which their information regarding the Social Security rules affects their retirement and wealth outcomes, and the implications of their imperfect knowledge on their welfare. We will also explore policies for improving Social Security literacy.

In this paper we first study people's knowledge of the Social Security system by analyzing data from two pilot surveys funded by a Seed Grant from Stony Brook’s Center for Survey Research (CSR) and MRRC. The first survey we put on the field in late August of 2007, collected information on 500 individuals about their knowledge of some

\footnotetext{
${ }^{1}$ Gustman and Steinmeier (2001), Blinder and Krueger (2004), Cao and Hill (2005), and Mastrobuoni (2006) focus on knowledge of the Social Security system, especially about expected benefit levels. Mitchell (1988), Starr-McCluer and Sundén (1999), Stevens and Chan (2005), Gustman, Steinmeier, and Tabatabai (2007) analyze pension knowledge. Lusardi and Mitchell (2005, 2007) focus on general financial literacy. Benjamin, Brown, and Shapiro (2006) analyze the link between cognition and preferences.
} 
of the most basic Social Security rules and how that knowledge was acquired. The follow-up was in the field in December of 2008, and we collected 507 observations. The follow-up part of the new survey allows us to test whether the respondents have retained the particular information which was given to them during the initial survey, and help us when modeling the information problem faced by individuals.

Second, we provide a measure of the cost brought about by Americans' lack of information on the Social Security system's rules. To that end, we present a framework in which we can compute the individuals' welfare gain from acquiring information regarding the Social Security system. We accomplish this by solving and simulating a life-cycle model of retirement behavior under different informational assumptions, and allowing for the endogeneity of the individuals' level of knowledge regarding the rules of the system. We find that the proportion of individuals who benefit from better information increases with age, and by age 60 this proportion reaches around $95 \%$ of individuals (it is only around $28 \%$ at age 40 ). At all ages, those who benefit from better information are willing to pay a sizable proportion of their wealth (more than 50\%) to have access to the best information possible.

Third, based on our results from these analyses, in particular the assessment of the cost of imperfect information, and equivalently the gains from full information regarding the Social Security system, we will discuss possible strategies that might increase individuals' awareness of the rules of the system, and evaluate which strategies would lead to more welfare-improving outcomes.

\section{Research Overview}

We have used a Seed Grant obtained from Stony Brook's CSR and funding from MRRC to conduct two phone surveys on a small representative sample of the U.S. adult population to gather information on respondents' knowledge of Social Security rules. The survey included about 20 questions on respondents' knowledge of several rules that affect their Social Security benefits, such as the age of early and normal retirement and the reduction factors with respect to the normal retirement, how they obtained their information, and their level of financial literacy with respect to calculations involving social security benefits, among others. A randomly chosen sub-group of respondents 
were also given the correct answer to one of the Social Security rule questions on the survey. One of the advantages of this survey is that it is not limited to an older subpopulation, so we can assess people’s knowledge of Social Security over an entire age profile.

We have analyzed the data from the original and new surveys to assess 1) the extent of the information problems regarding the basic rules of the Social security system, 2) whether the prevalence of informational gaps differs across demographic and socioeconomic groups, and 3) how it varies with the level of financial literacy in the population. The pilot survey also included a standard battery of socio-economic, and demographic questions, as well as health and longevity expectations questions.

The results from the survey show that there is significant variation in people's knowledge of Social Security rules, and that this knowledge varies by the year of the survey. For example, only 42\% percent of the respondents interviewed in 2007 correctly answered the question "What is the youngest age at which an eligible worker can apply for his or her own Social Security retirement benefits?” but this percentage goes above $54 \%$ in 2008 , and almost to $56 \%$ among those re-interviewed in that year. We can see in the case of this relatively simple question, a 2008 effect, which we interpret as showing that due to being an election year it might be that even among new interviewees the level of knowledge had increased, appears. The percentage of individuals answering correctly varies considerably by age, and in 2008 varies from around 20\% among those 18 to 34, to around $72 \%$ for those 55 to 64 . The variation with respect to income is considerably lower.

A much lower percentage, 22.8\%, gave the correct answer in 2007 to "What is the maximum age at which you can claim Social Security retirement benefits so that Social Security will adjust your benefits upward?” and the percentage is almost identical to the new respondents of 2008, however, it goes up to $45 \%$ among those re-interviewed in 2008.

The latter pattern appears throughout the survey, for example regarding the minimum number of years necessary to be eligible to receive benefits, or the incidence of the earnings test, showing a large increase in knowledge among the re-interview sample, which we interpret as implying considerable promise of policy recommendations the 
objectives of which is to encourage individuals to go and find out information which could be relevant to them.

Additionally, we find that $55.7 \%$ of the individuals who were already receiving some kind of government benefits, responded 'yes' to the question "Do you think that you should have had more information about possible changes to the system that could affect you?" suggesting that the informational problems may have resulted in costs, which were observed by the individual ex post.

The second step in our methodology is to compute the cost that an individual incurs due to his/her lack of information on Social Security rules by comparing his/her welfare under full information to the welfare under imperfect information. We use the full information characterization of the model as the benchmark model which builds upon the work of Benitez-Silva and Heiland (2007), and Benitez-Silva et al. (2009), but adds employment uncertainty. In that case individuals choose how much to consume and save, how much to work and when to retire, and when to claim benefits from Social Security under the assumption that they have perfect knowledge of all the retirement incentives.

We then present departures from the full information assumption and provide several possible characterizations of partial information regarding Social Security rules by incorporating recent advances in decision theory and game theory. For example, Fagin and Halpern (1988), and Modica and Rustichini $(1994,1999)$ introduce new logics for belief and knowledge to differentiate full awareness and partial awareness. Heifetz, Meier and Schipper (2006) and Li (2006a) characterize multi-person information structures with unawareness. Feinberg (2004, 2005), Heifetz, Meier and Schipper (2007), Li (2006b), Rego and Halpern (2007) define solution concepts for games with unaware players.

Generally speaking, under incomplete information individuals aggregate all possibilities without differentiating them (for example assuming that the adjustments for early and late retirement are identical), resulting in biased assessments of the trade-offs they face. On the other hand, under unawareness, they completely ignore some of the possibilities, and thus cannot exploit any relevant information. One key characterization we explore, which is an extreme case of unawareness, is when individuals do not know 
anything about the details of the system, and they decide when to claim Social Security benefits based on what they observe others to be doing.

The comparison of individuals' welfare in full information and partial information cases allow us to compute the welfare gain resulting from moving from unawareness to the full information solution. Using this approach, we also compute bounds for the social cost of financial illiteracy regarding the Social Security rules, and at the same time provide a policy tool for the government when considering policy interventions about information issues of the social insurance system.

We characterize the individual's problem using a structural dynamic life-cycle model of retirement behavior under uncertainty. The structural approach employed in the project allows us to control for the possible endogeneity of information on Social Security. An individual's information on Social Security may have been endogenously determined based on his/her cost of acquiring information. Therefore, we incorporate into the model the individual's cost of knowledge acquisition, which is likely to vary with education and income.

The dynamic nature of the model allows us to follow changes in wealth accumulation and labor supply decisions over time. When people make decisions under imperfect knowledge, they may change behavior and take corrective measures when they find out that their expectations diverge from actual realizations. In our model, people may invest more in learning about their Social Security benefits as they near retirement. If they realize that their expectations of benefits are different from their actual benefits, they may accelerate wealth accumulation or postpone retirement.

The final step of our research uses the results from the pilot and new surveys, and the welfare implications of the dynamic structural model to discuss policy alternatives aimed at increasing the public's knowledge of the Social Security system. The policies that we consider include customizing the Social Security statement highlighting different messages according to the individual's characteristics, such as age, family situation, or earnings. For example, young individuals might receive highlighted messages regarding the features of the system on which they lack information based on our findings from the pilot and new surveys, while older individuals might receive more detailed information about the consequences of claiming benefits and continuing working. We hypothesize 
that we will find considerable heterogeneity in the information structure of individuals, and Social Security can exploit this heterogeneity to reach the population with more targeted messages.

The next section gives some details about the surveys we put in the field in 2007 and 2008 to assess the level of knowledge regarding simple Social Security rules by Americans, and section four presents the dynamic model we will use to assess the welfare consequences of lack of knowledge. The final section of the paper concludes.

\section{Results from the Surveys on Social Security Knowledge}

We have conducted two telephone surveys through Stony Brook’s Center for Survey Research during August 2007 (funded with a Seed Grant from the V.P. for Research at SB), and December 2008 (funded by MRRC). Samples of 500 and 507 observations, weighted to be nationally representative. 179 observations of the 2008 survey were reinterviews.

Here we will analyze some of the responses (those we believe to be the simplest questions) and we will discuss the pattern that emerges regarding the level of knowledge over time for those who are re-interview, as well as the pattern by age, education, and income categories.

Tables 1 and 2 show the responses to the question regarding the Early Retirement Age, and we can see that only around $50 \%$ of individuals get this answer right, and we can also see a considerable improvement from 2007 to 2008, maybe suggesting a time effect product of the fact that 2008 was an election year, in which some discussions of Social Security reached the debate. There is some re-interview effect for this question, but it is small.

Figure 1 focuses on the responses to the knowledge of the NRA (also known as Full Retirement Age), which is considerably better, and shows some re-interview effect. This latter effect is quite in Figure 2 regarding the maximum retirement age (age 70), reinterviewers do much better, and the time effect all but disappears, suggesting that might only affect the simpler issues. Notice, however, that the level of exact knowledge of this item is quite low. 
Figure 3 shows the low level of knowledge regarding the minimum eligibility requirements to receive retirement benefits, and again shows a clear re-interview effect.

Figures 4 and 5 deal with a more complex provision, that of the earnings test, and we can see again that re-interviewers do better, but overall individuals do not do much better than a simple coin toss, and the natural improvement with the second question which provides some information to individuals.

Table 1. Responses to the question: What is the youngest age at which an eligible worker can apply for his or her own Social Security retirement benefits? (All respondents 2007 and 2008)

\begin{tabular}{|l|l|l|l|}
\hline Response & Frequency & Percent & Cummulative percent \\
\hline Less than 50 & 52 & 8.37 & 8.37 \\
\hline 51 to 61 & 108 & 17.39 & 25.76 \\
\hline Exactly 62 & 298 & 47.99 & 73.75 \\
\hline 63 to 64 & 15 & 2.42 & 76.17 \\
\hline Exactly 65 & 83 & 13.37 & 89.53 \\
\hline Over 66 & 37 & 5.96 & 95.49 \\
\hline Don't know & 28 & 4.51 & 100 \\
\hline Total & 621 & 100 & \\
\hline
\end{tabular}


Table 2. Responses to the question: What is the youngest age at which an eligible worker can apply for his or her own Social Security retirement benefits? (by type of respondent)

\begin{tabular}{|c|c|c|c|c|}
\hline \multirow[b]{2}{*}{ Response } & \multicolumn{3}{|l|}{ Sample } & \multirow[b]{2}{*}{ Total } \\
\hline & $\mid \begin{array}{l}2007 \\
\text { respondents }\end{array}$ & $\begin{array}{l}2008 \text { new } \\
\text { respondents }\end{array}$ & $\begin{array}{l}2008 \text { re- } \\
\text { interviewed } \\
\text { respondents }\end{array}$ & \\
\hline Less than 50 & $9.57 \%$ & $7.5 \%$ & $6.19 \%$ & $8.37 \%$ \\
\hline 51 to 61 & $19.14 \%$ & $15.5 \%$ & $15.46 \%$ & $17.39 \%$ \\
\hline Exactly 62 & $41.98 \%$ & $54 \%$ & $55.67 \%$ & $47.99 \%$ \\
\hline 63 to 64 & $2.47 \%$ & $3 \%$ & $1.03 \%$ & $2.42 \%$ \\
\hline Exactly 65 & $15.43 \%$ & $10 \%$ & $13.4 \%$ & $13.37 \%$ \\
\hline Over 66 & $5.56 \%$ & $6 \%$ & $7.22 \%$ & $5.96 \%$ \\
\hline Don't know & $5.86 \%$ & $4 \%$ & $1.03 \%$ & $4.51 \%$ \\
\hline \# Obs. & 324 & 200 & 97 & 621 \\
\hline
\end{tabular}

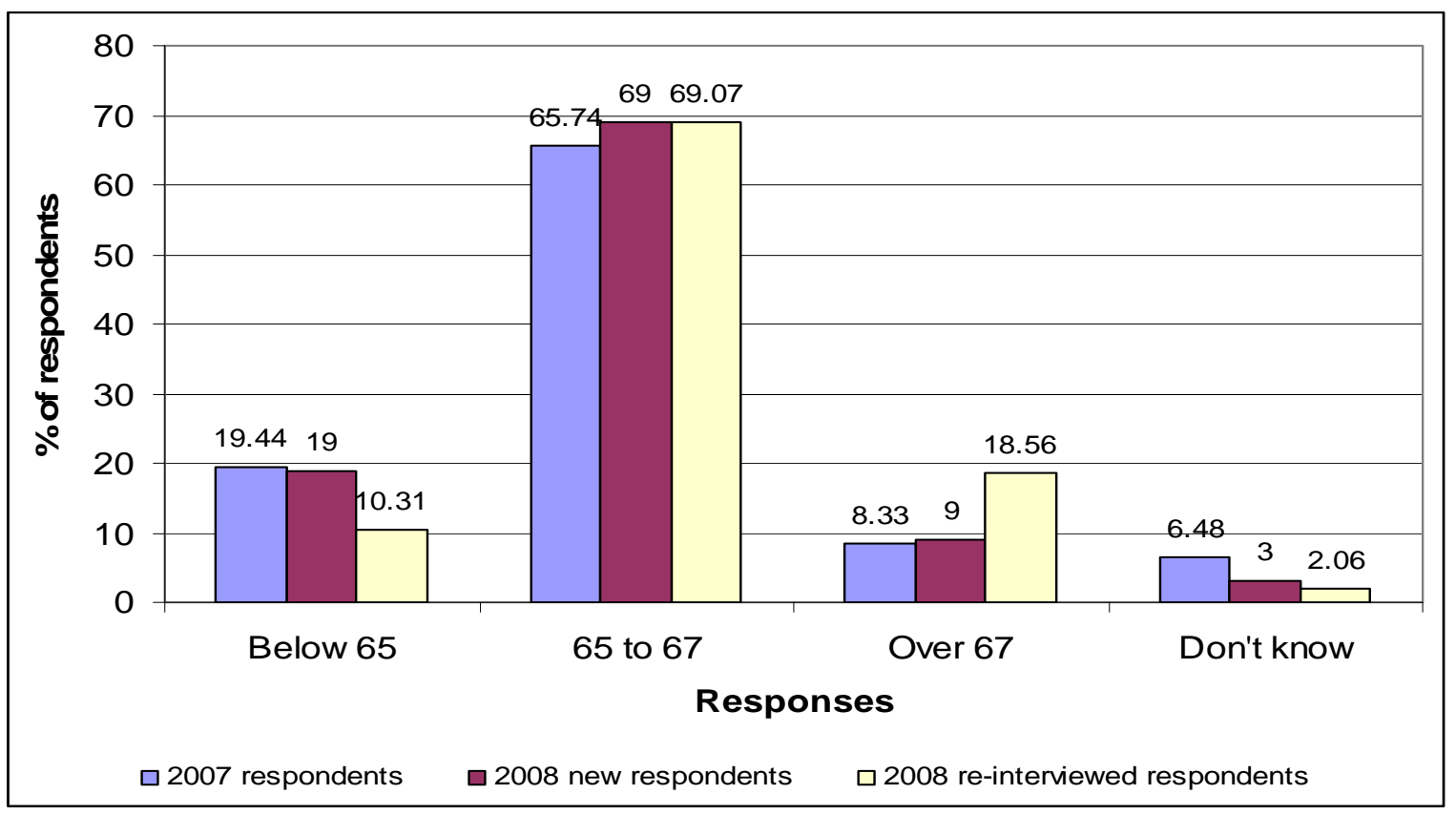

Figure 1. What is the earliest age of retirement at which Social Security would pay you full, unreduced benefits? 


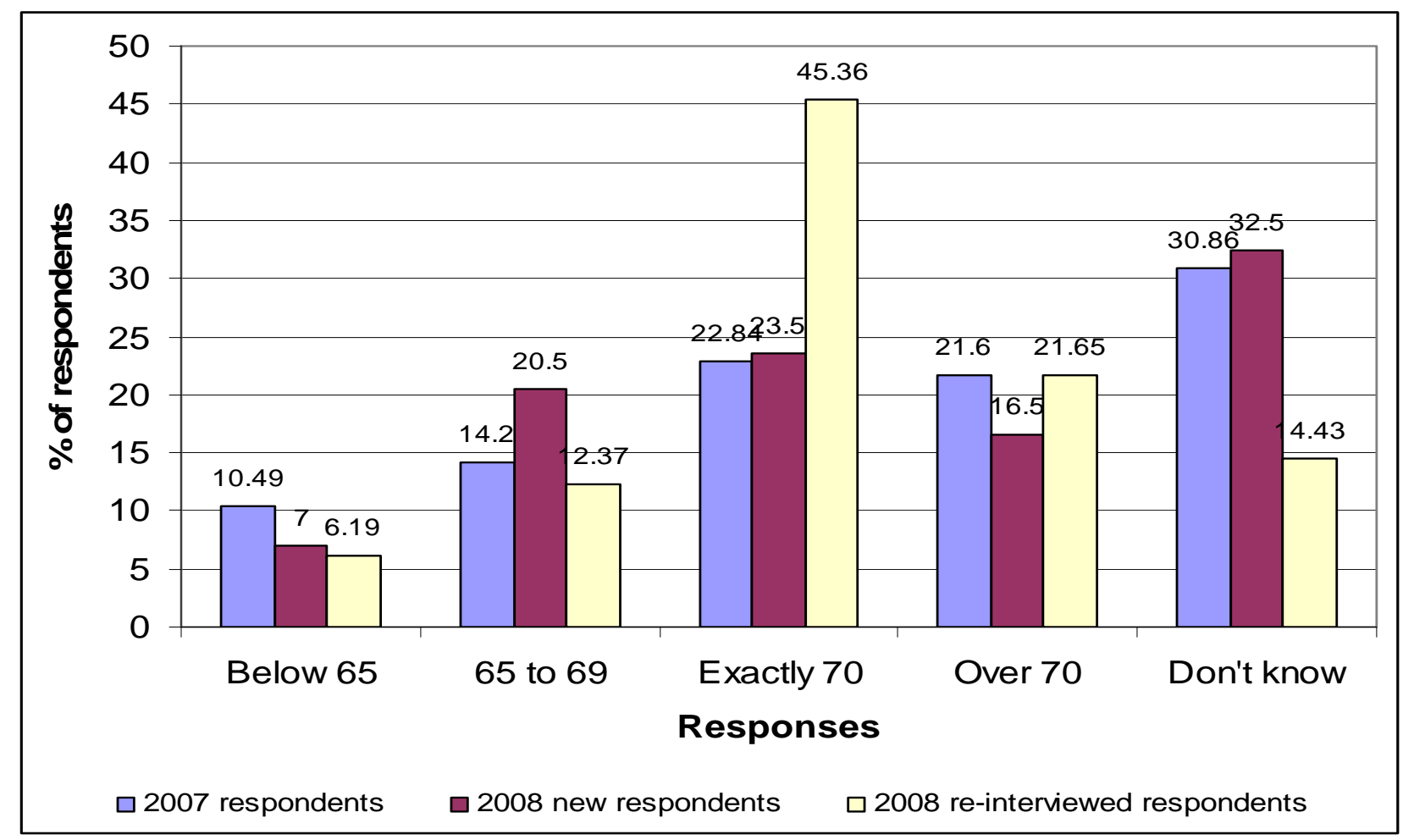

Figure 2. What is the maximum age at which you can claim Social Security retirement benefits so that Social Security will adjust your benefits upward [because of the delay in claiming benefits]?

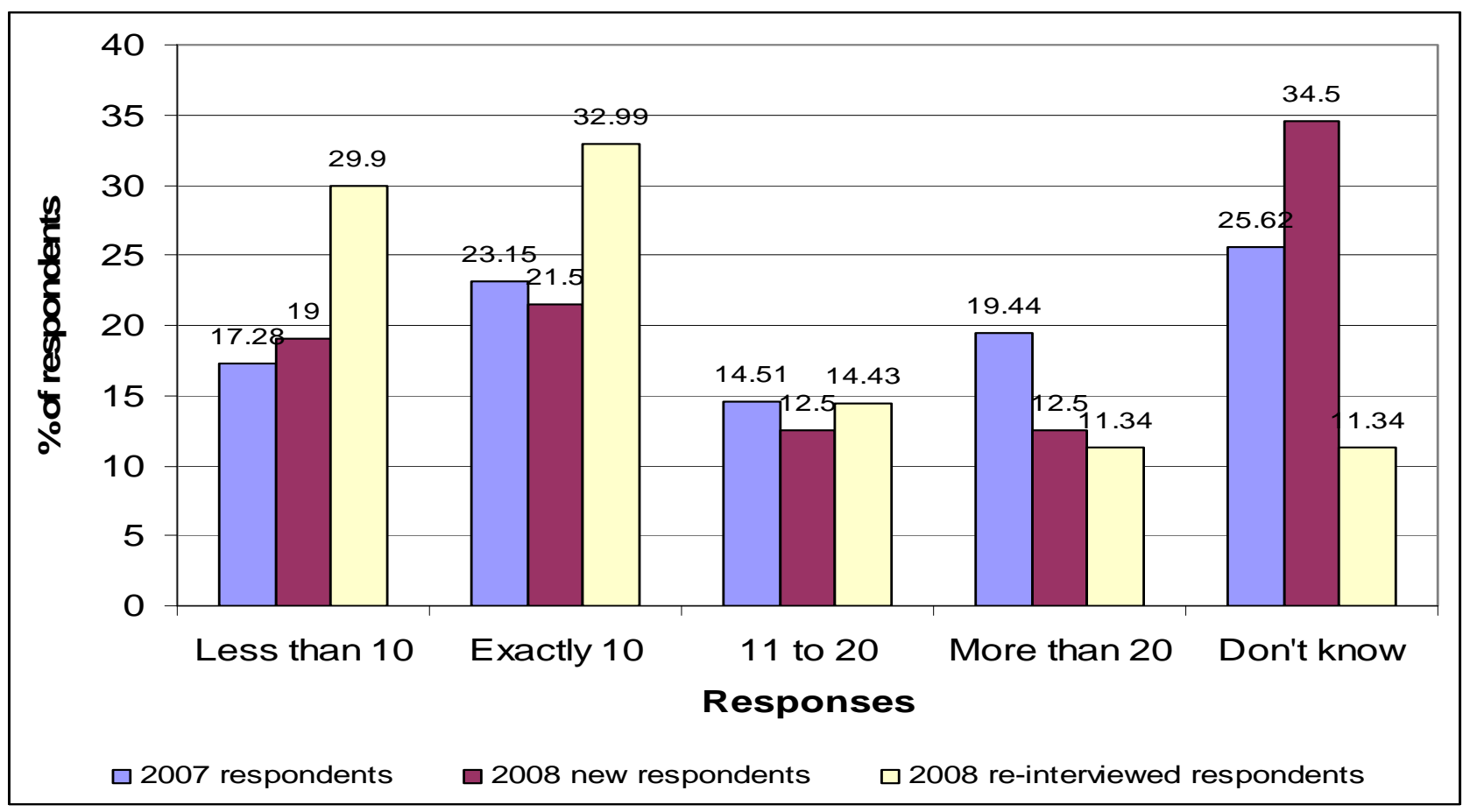

Figure 3. What is the minimum number of working years that qualify you to receive Social Security Retirement Benefits? 


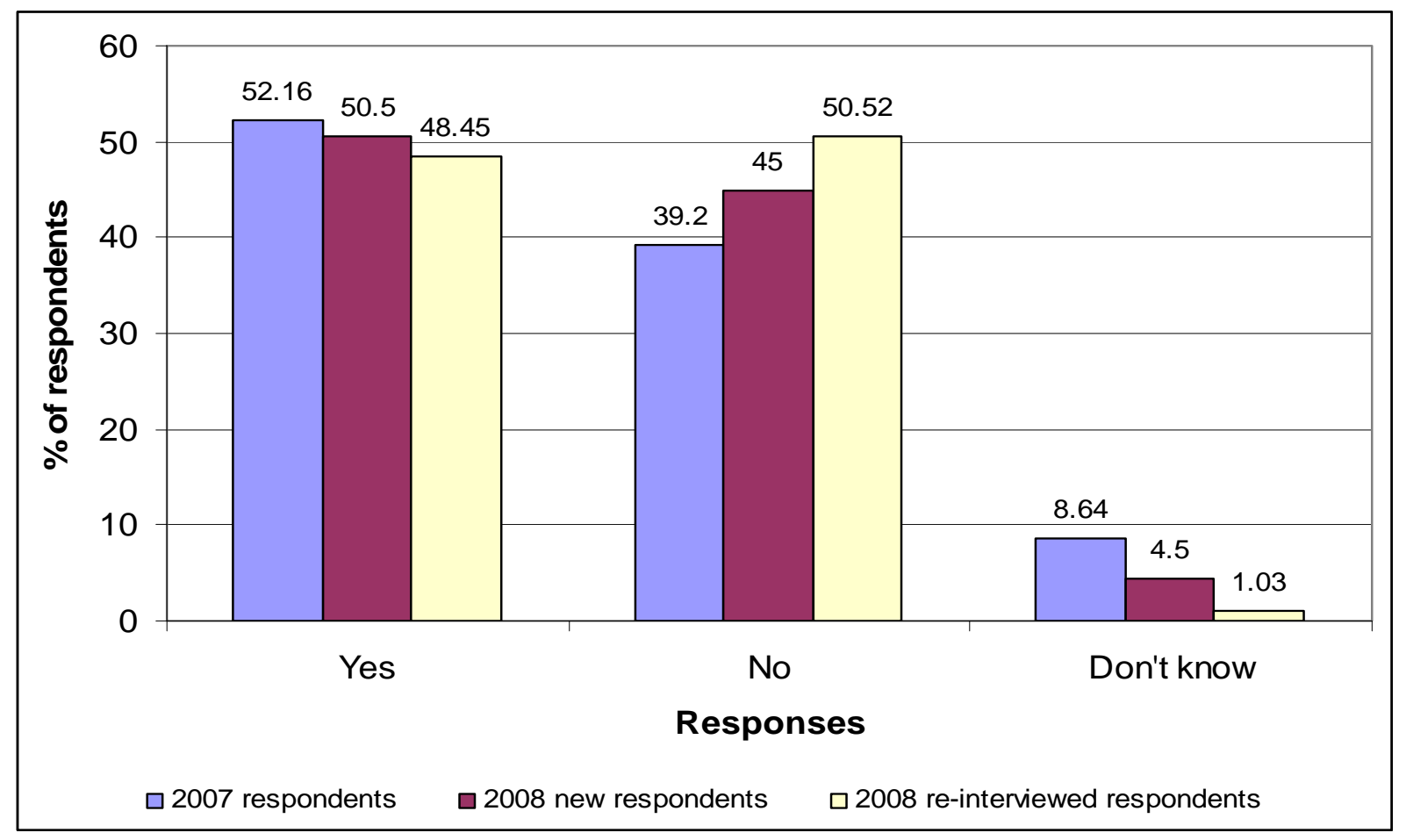

Figure 4. If you earned $\$ 10,000$ in a given year from working after you began receiving Social Security Retirement Benefits at age 62, do you think your Social Security benefits would be reduced?

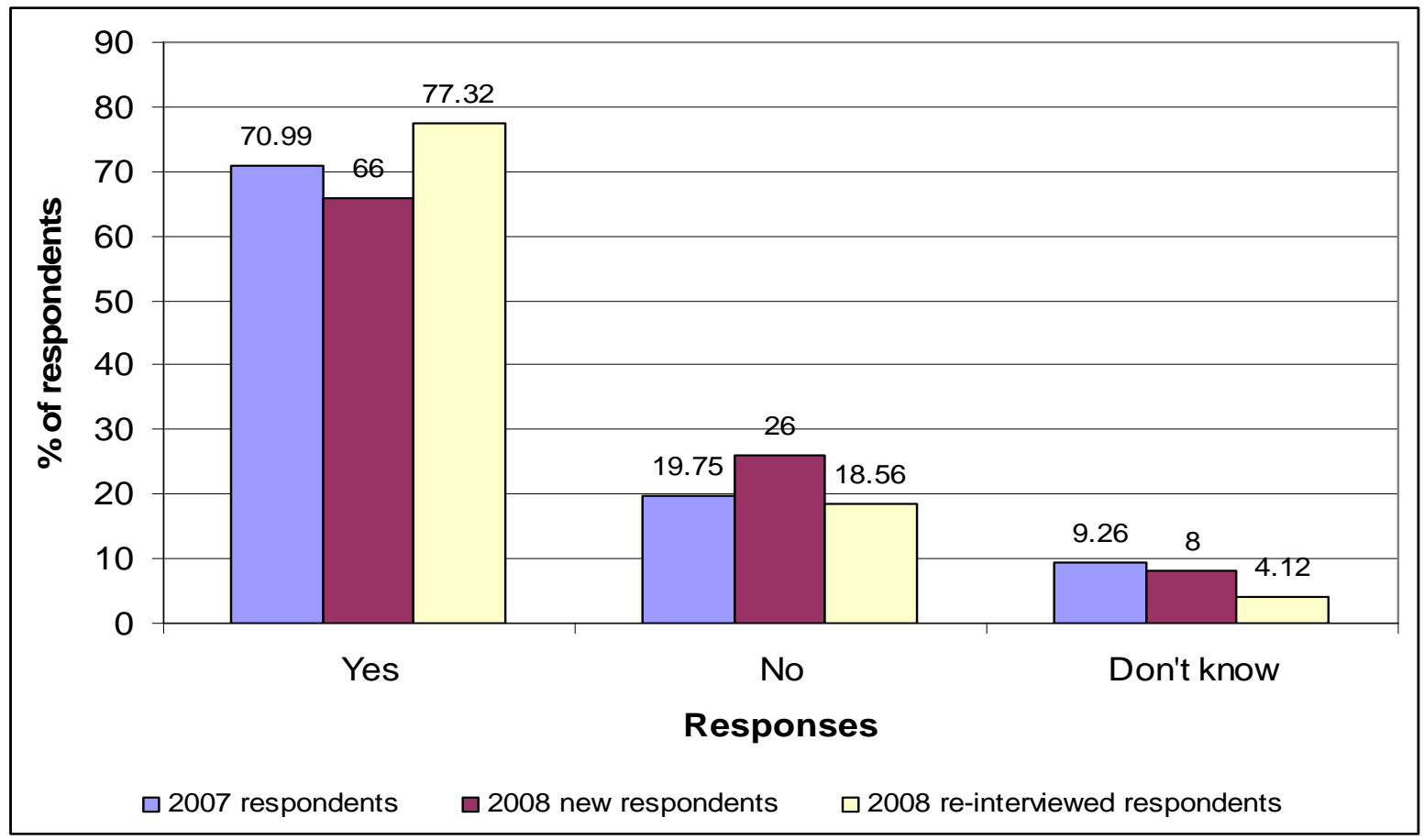

Figure 5. What about if you earned $\$ 20,000$ in a given year from working after you began receiving Social Security Retirement Benefits at age 62, do you think your Social Security benefits would be reduced? 
Figures 6 to 9 analyze how the knowledge on the Early and Maximum Retirement ages changes with age and educational categories. As expected in both dimensions knowledge improves as age and education increases, and we can observe a time effect when comparing 2007 and 2008, but again mostly the product of those re-interviewed. Notice that even among individuals very close to retirement the knowledge of the Maximum Retirement Age is surprisingly low with only around $40 \%$ of those in the 55 to 64 age range getting it right, and even for the Early Retirement Age it only reaches around 70\% for those around that age who have not claimed yet.

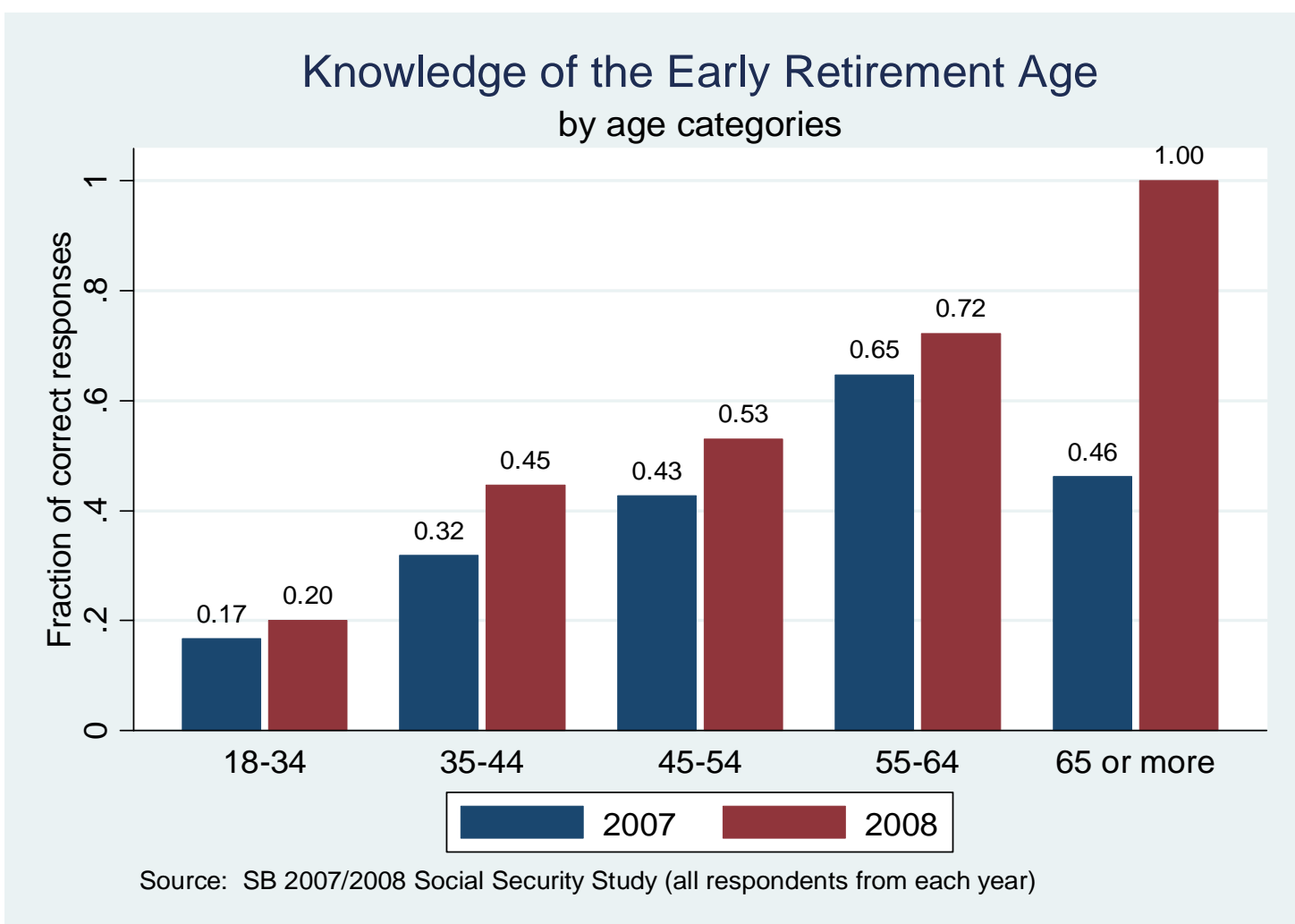

Figure 6. Knowledge of the ERA by age categories 


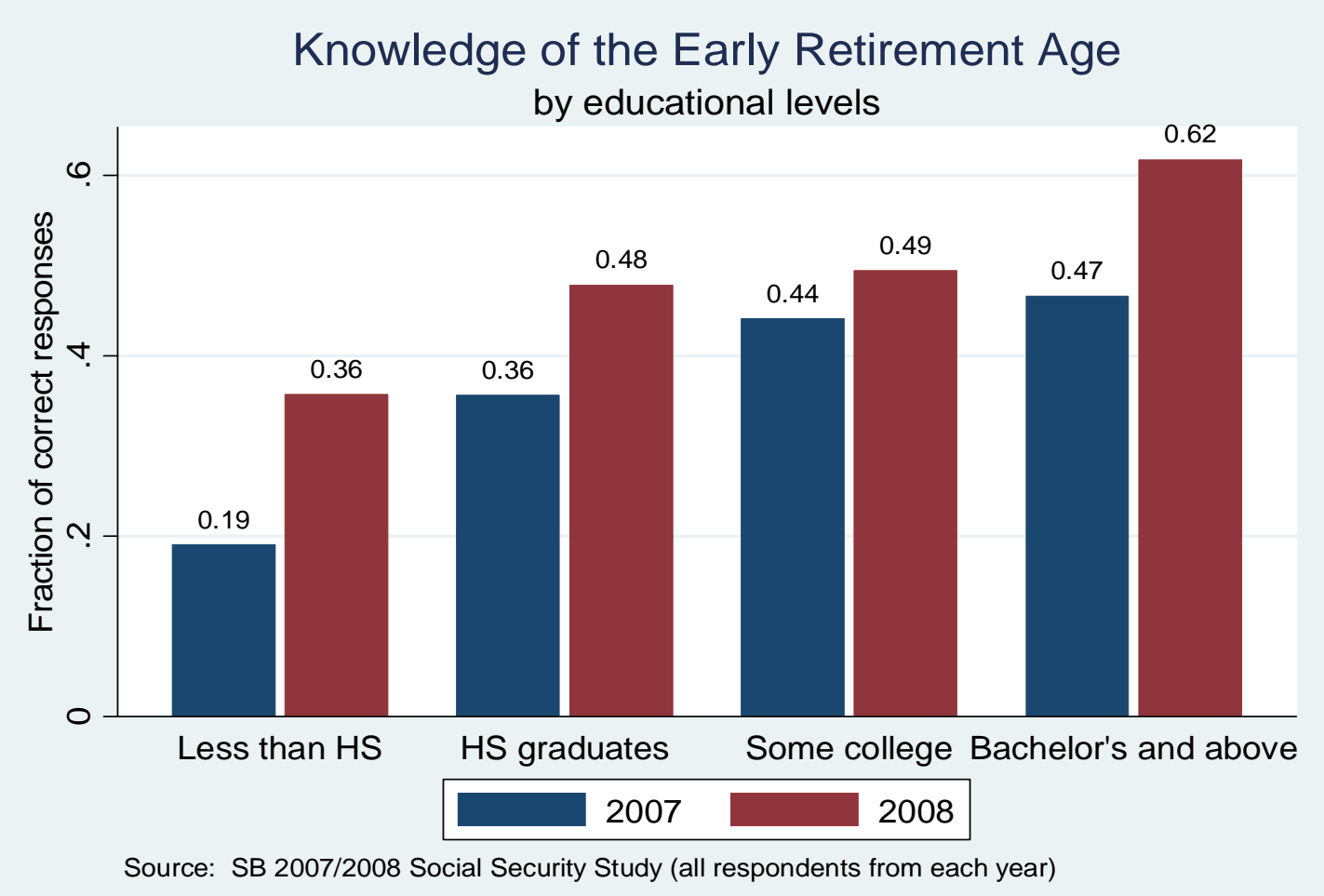

Figure 7. Knowledge of the ERA by Educational categories

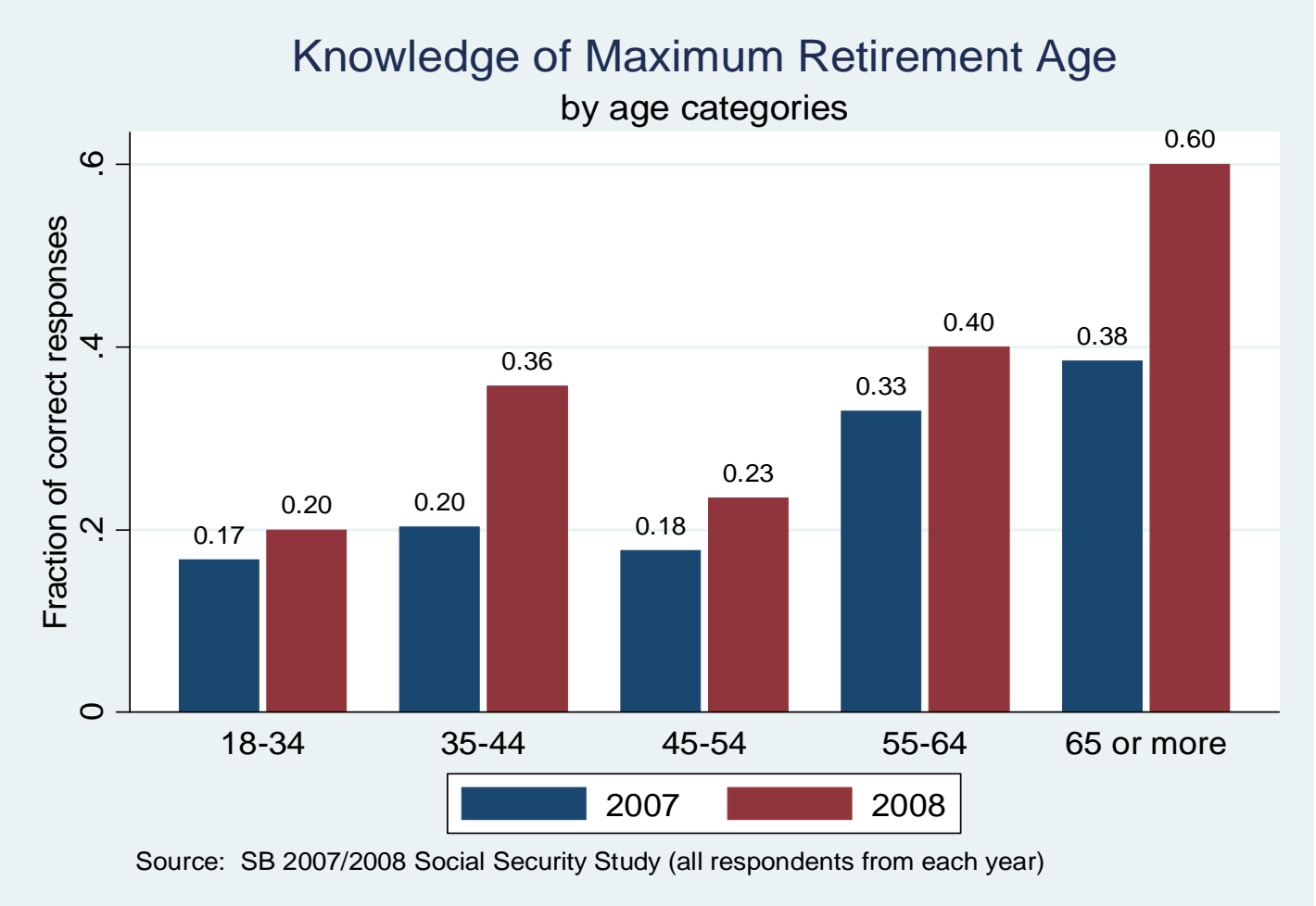

Figure 8. Knowledge of the MRA by age categories 


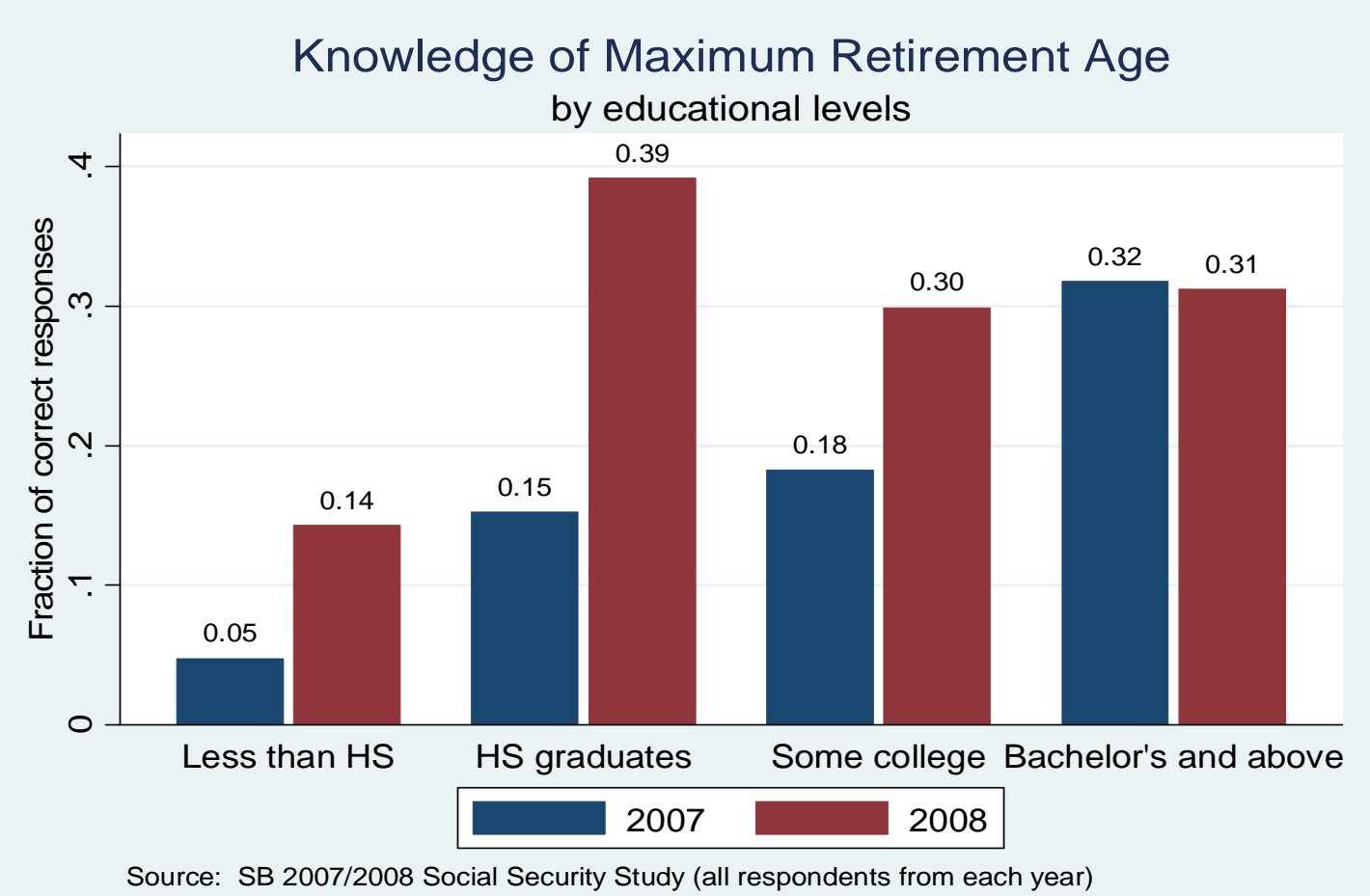

Figure 9. Knowledge of the MRA by educational categories

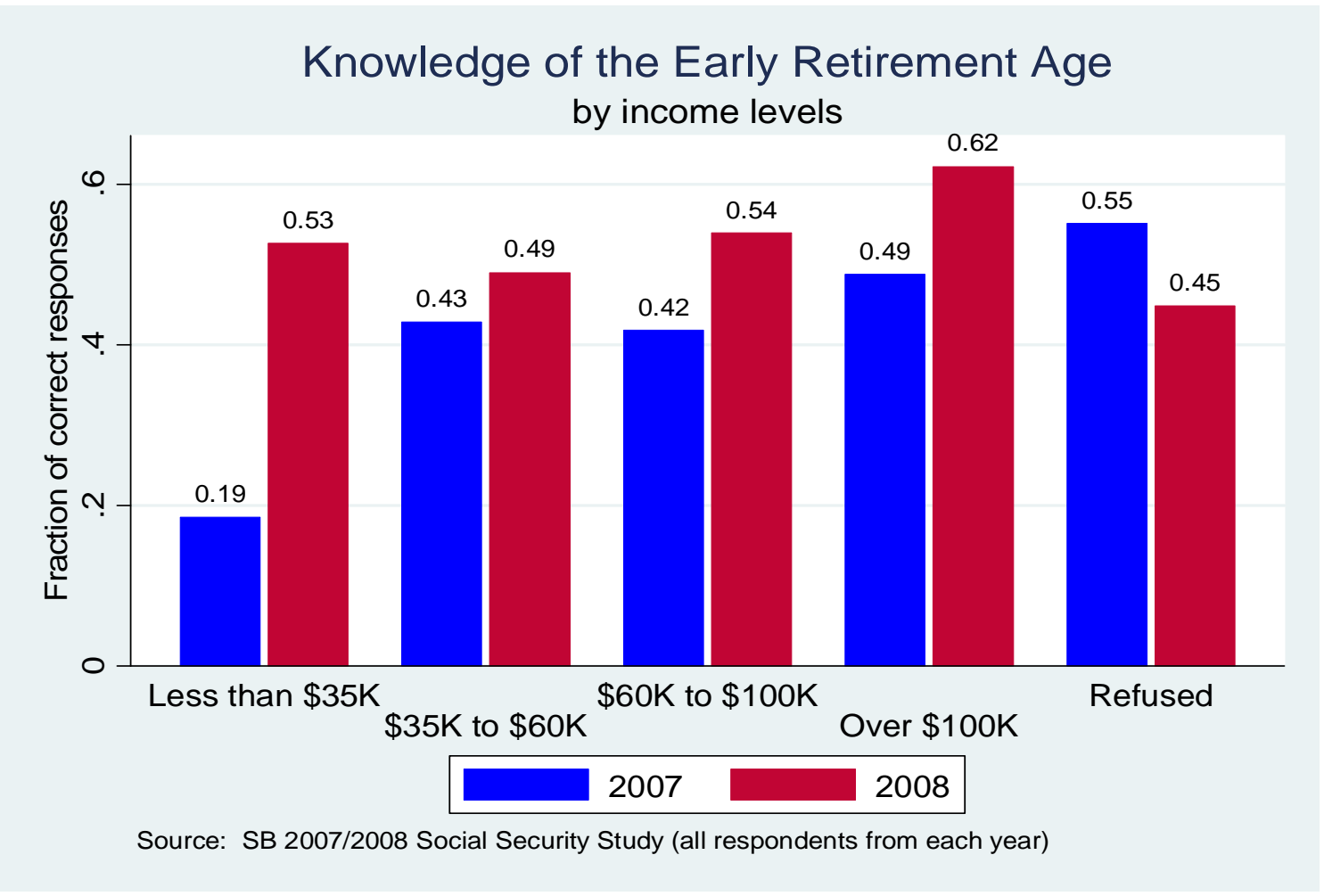

Figure 10. Knowledge of the ERA by Income categories 


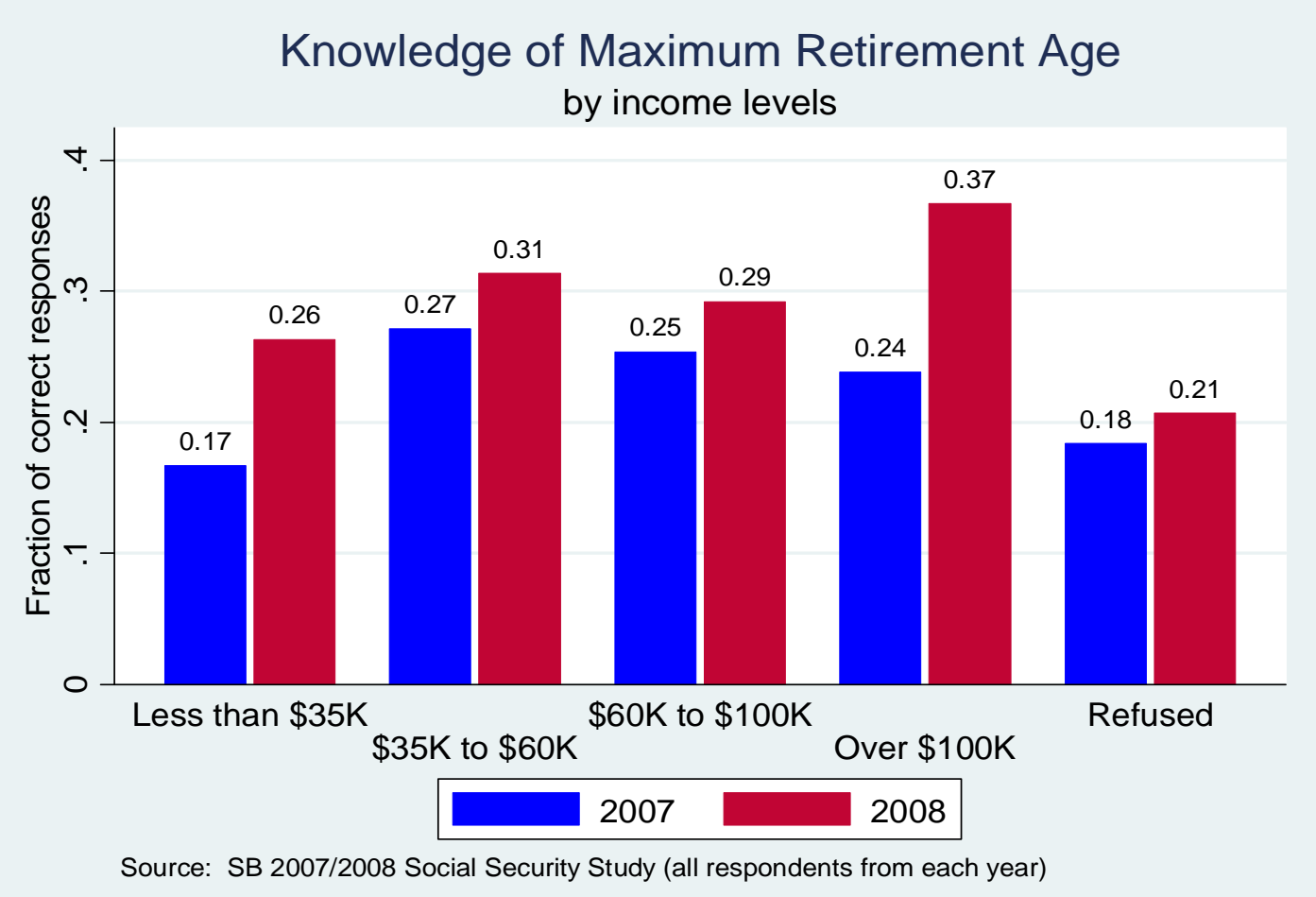

Figure 11. Knowledge of the MRA by Income categories

Figures 10 and 11, explore the relationship between knowledge and income, and here the results are much less clear, with only those who made over 100k doing clearly better than the rest. The results also suggest that those who benefit the most from the reinterviews are the lower income categories, which is quite encouraging as a policy conclusion.

We then conclude that the general level of knowledge of some of the simpler Social Security rules is quite low, even among older, educated and higher income individuals, and the lack of knowledge gets worse as the type of information increases in complexity or refers to issues that happen later in the process. We also conclude that there is a clear re-interview effect, which is quite encouraging since most of these individuals where not given any answers to the questions, and yet they do much better more than a year after the first interview.

One possible reaction to all this evidence is to wonder if this matters much. I might not know the early retirement age is 62, or I might not know what is my exact Normal Retirement Age, but this might have small welfare consequences for me, small 
enough not to compensate the cost of acquiring accurate information. We try to explore this issue in the next section.

\section{The Dynamic Life-Cycle Model}

The ultimate objective of setting up a model of retirement behavior is to be able to perform a welfare analysis of different information structures. This is important because we do not want to stop our analysis at the point of showing that individuals have limited knowledge of the details of the system. While this is interesting, and we are one of the first researchers to show the limited knowledge regarding some of the less complicated and supposedly common knowledge features of the system, showing that this is the case without assessing wether this is a serious matter in terms of what the agents are losing by not acquiring the additional knowledge is in our opinion leaving the research half done.

The welfare analysis is key, because it could be easily conjectured that the gains from acquring all the necessary knowledge to behave optimally might be too small, and therefore for most individuals could never compensate the cost of acquiring such knowledge. If on the other hand, we find that the gains from having good information are large, it would have to be argued that the costs are very large, maybe because of how tough is for individuals to access information or maybe they are misperceiving the welfare gains they could be enjoying. In any case, large welfare gains would suggest that policies targetted at incresaing the understanding of the system would be worth our efforts and resources.

In order to make those important welfare calculations we need two things. First a benchmark model. Such a model has to have several properties, but mainly has to be a fairly good approximation to actual behavior. Ironically, finding a good model under the assumption of perfect knowledge of the incentive structure to reflect a reality in which we know individuals do not have such good information is bound to require a number of additional mechanisms to match the data, like a system of beliefs about the future, which we model as sources of uncertainty. Second, we need to explicitly model an alternative informational structure to compare to the benchmark model. There are many possible informational structures consistent with what we have observed in our surveys, and we 
have chosen, for the moment, to illustrate the results of assuming one of them, but as we will discuss below there are others we can analyze and study.

We build upon an established framework to analyze retirement behavior, modeling the complete set of incentives provided by the Earnings Test and ARF adjustment. The model used in this paper is closely related to models presented in Rust and Phelan (1997) and Benítez-Silva, Buchinsky, and Rust (2003, 2006). Rust and Phelan (1997) did not model consumption and savings decisions, but did estimate the parameters of the model, using a Nested Fixed-Point algorithm, instead of calibrating them. Benítez-Silva, Buchinsky, and Rust $(2003,2006)$ and as mentioned earlier Benítez-Silva and Heiland (2007), and Benítez-Silva et al. (2009) present the most closely related models, which are calibrated to match aggregate data and household level data from the Health and Retirement Study. Benítez-Silva, Buchinsky, and Rust (2003, 2006) model the Social Security Disability Insurance decisions on top of the OASI incentives. Unlike the structural model developed in the present paper, these earlier models (or any other structural models we are aware of) do not explicitly account for the possibility of affecting the Actuarial Reduction Factor, or assess the consequences of different informational structures. Our model also shares a number of characteristics with the work of French (2005), van der Klaauw and Wolpin (2008), and Blau (2008), among other researchers who solve, simulate, and in some cases estimate, dynamic retirement models under uncertainty.

The model presented here predicts individuals' labor supply, benefit initiation and receipt, and earnings. The model also predicts wealth accumulation and consumption decisions, but we focus here for the moment on the claiming decision. As discussed in the papers mentioned above, the simulations of the model are broadly consistent with empirical evidence on a variety of measures.

\section{Short Description of the Model}

We assume that individuals maximize the expected discounted stream of future utility, where the per period utility function $u(c, l, h, t)$ depends on consumption $c$, leisure $l$, health status $h$, and age $t$. We specify a utility function for which more consumption is better than less, with agents expressing a moderate level of risk aversion. The flip side of 
utility of leisure is the disutility of work. We assume that the utility (disutility of work) is an increasing function of age, is higher for individuals who are in worse health than individuals who are in good health, and is lower for individuals with higher human capital measured by the average wage. In addition, we assume that the worse an individual's health is, the lower their overall level of utility is, holding everything else constant. Moreover, we assume that individuals obtain utility from bequeathing wealth to heirs or to institutions after they die. This model assumes that individuals are forward looking, and discount future periods at a constant rate $\beta$, assumed here to be equal to 0.96. The model also allows for a variety of sources of uncertainty, like lifetime uncertainty, health uncertainty, wage uncertainty, and employment uncertainty. The latter is an innovation of this paper with respect to those we are directly building upon. To model this uncertainty we use the empirical distribution of transitions from employment to unemployment using the CPS from 1986 to 2006.

Any person who is not already receiving Social Security Old Age benefits is eligible to apply for OASI benefits. Individuals with at least 40 quarters of earnings covered for OASI before reaching their $62^{\text {nd }}$ birthday are eligible to apply, and benefit award is guaranteed. In the present version of the model, we allow decisions to be made on an annual basis and assume no lag between application date and date of first receipt.

Calculation of benefits and the reduction factors are as explained in Benítez-Silva and Heiland (2007), assuming an NRA of 66. In particular, the number of checks received in a year depends on the earnings after claiming: The number of checks (or the benefit amount on some checks received towards the end of the period) are reduced, reflecting the 50\% rate on labor incomes exceeding the Earnings Test limit between 62 and the January of the year a person turns 66 (33\% thereafter). In other words, adjustments to benefits and ARFs occurs in accordance with the earnings and the Earnings Test limit, and we do not consider the possibility that beneficiaries ask Social Security for a reduction of benefits or return benefits received. Even though we set up an annual decision-making process, the Social Security Earnings Test is enforced semiannually; that is, the benefits received by a beneficiary are adjusted, after reaching the NRA, for the earnings in excess of the Earnings Test limit, as long as six months or more of benefits were withheld in the years between the early and normal retirement 
ages.

\section{Model Details}

We solve the dynamic life-cycle model by backward induction, and by discretizing the space for the continuous state variables. The terminal age is 100 and the age when individuals are assumed to enter the labor force is 21. Prior to their $62^{\text {nd }}$ birthday, agents in our model make a leisure and consumption decision in each period. At 62 and until age 70, individuals decide on leisure, consumption, and application for OASI benefits, denoted $\left\{l_{t}, c_{t}, b_{t}\right\}$, at the beginning of each period, where $l_{t}$ denotes leisure, $c_{t}$ denotes consumption, which is treated as a continuous decision variable, and $b_{t}$ denotes the individual's Social Security benefit claiming decisions. After age 70 it is assumed that all individuals have claimed benefits, and again only consumption and leisure choices are possible. Leisure time is normalized to 1 , where $l_{t}=1$ is defined as not working at all, $l_{t}=.543$ corresponds to full time work, and $l_{t}=.817$ denotes part-time work. These quantities correspond to the amount of waking time spent non-working, assuming that a full-time job requires 2,000 hours per year and a part-time job requires 800 hours per year. We assume two possible values for $b_{t}$. If $b_{t}$ equals 1 the agent has initiated the receipt of benefits. If the individual has not filed for benefits or is not eligible then $b_{t}$ is equal to 0.

If benefits are claimed before the NRA, the monthly benefit amount is calculated similar to Equation 1. For a NRA of 66 years, the reduction factor if claimed at 62 is $75 \%, 80 . \%$ if claimed at $63,86.67 \%$ if claimed at 63 , and $93.33 \%$ if claimed at 65 . Due to the Earnings Test, benefit initiation between the ERA and the NRA does not necessarily imply benefit receipt, nor is the reduction in the benefit rate necessarily permanent after the NRA as a result of the adjustment of the ARFs, as discussed above (see Equation 2). In particular, we use an annual Earnings Test limit of \$12,480 between 62 and 65 and $\$ 33,240$ between 65 and 66 (these numbers reflect the 2006 limits). In the former period, benefits are reduced at a rate of \$1 per \$2 of earnings above the limit, and \$1 per \$3 of earnings above the limit for the latter period. These are the correct rules for someone who turns 66 in December. Because those whose birthday is earlier in the year face the higher 
limit and lower tax rate for less than a year (January to month of birthday), we have also simulated two alternative versions, one with the $\$ 12,480$ limit throughout, and another using $\$ 20,760$, the midpoint between the two limits, and a tax rate of $50 \%$. The results of these models do not differ markedly from those presented in Table 5 and are available from the authors upon request. Those claiming after 66 earn the delayed retirement credit. We model it following the rates faced by the 1943-54 cohorts, of $2 / 3$ of $1 \%$ for each month not claimed between age 66 and 70 .

We also incorporate a detailed model of taxation of other income, including the progressive federal income tax schedule (including the negative tax known as the EITCEarned Income Tax Credit), and state and local income, sales, and property taxes.

Individuals whose combined income (including Social Security benefits) exceeds a given threshold must pay federal income taxes on a portion of their Social Security benefits. We incorporate these rules in our model as well as the $15.75 \%$ Social Security payroll tax.

The model allows for four different sources of uncertainty: (a) lifetime uncertainty: modeled to follow the Life Tables of the United States with age-specific survival probabilities; (b) wage uncertainty: modeled to follow a log-normal distribution, function of average wages as explained in more detail below; (c) health uncertainty: assumed to evolve in a Markovian fashion using empirical transition probabilities from a variety of household surveys, including the NLSY79 and the HRS; (d) employment uncertainty: modeled following the empirical transition probabilities in the CPS from employment to unemployment at all ages, and assuming individuals who lose their jobs receive half a year of unemployment benefits. The random draws to simulate these uncertainties are the same for all the models compared in this paper, such that the differences presented are due only to the changes in the incentive schemes.

The state of an individual at any point during the life cycle can be summarized by five state variables: (i) current age $t$; (ii) net (tangible) wealth $w_{t}$; (iii) the individual's Social Security benefit claiming state $s s_{t}$; (iv) the individual's health status, and (v) the individual's average wage, $a w_{t}$.

This translates into a problem with over half a million states in which to solve the model (80 periods, 15 discretized wealth states, 8 discretized average wage states, 3 
health states, and 18 Social Security states). We are able to solve this model and simulate it 10,000 times in under 20 minutes in a Dual-Processor Linux Machine with $3.6 \mathrm{GHz}$ Xeon Processors using Gauss, and exploiting its capability to link dynamic libraries written in $\mathrm{C}$ by the authors and some of their co-authors. These $\mathrm{C}$ libraries perform over 95\% of the computations involved in solving and simulating these models. The code used for these simulations is available upon request, and will eventually be available on the Web.

For computational simplicity, we assume that decisions are made annually rather than monthly, but we allow for the benefit adjustments due to earnings above the Earnings Test limit to happen semi-annually. This means that, although individuals can only decide to claim benefits at the time they turn 62, 63, etc., their Social Security state can be updated every year, depending on their labor earnings, to reflect that their benefits will be adjusted for benefits withheld for periods of six months or one year. Since the adjustment in benefits becomes effective only after they reach the NRA, individuals still receive benefits at the original claiming rate in the period between the time of withholding of benefits until the NRA, consistent with current rules.

The $s s_{t}$ variable can assume up to 14 mutually exclusive values between 62 and 66: $s s_{t}=0$ (not entitled to benefits), $s s_{t}=62$ (entitled to OASI benefits at the ERA), and $s s_{t}=62.5,63,63 n, 63.5,64,64 n, \ldots ., 65.5,66,66 n$ represents the remaining 12 Social Security states corresponding to the level of benefits individuals will receive when they reach the NRA. For individuals who decide to claim after the NRA, $s s_{t}$ can take four additional values, age 67 to 70, since everyone is assumed to claim no later than age 70 . We created an additional (implicit state) variable, $s s n_{t}$, which can assume up to 5 mutually exclusive values: $s s n_{t}=0$ (all benefits received; that is, no benefits withheld), $s s n_{t}=1$ (representing an original claim at age 62 of someone who had some benefits withheld; this applies, for example, to individuals with a $s s_{t}$ equal to $62.5,63 n$, or $64 n$ ), $s s n_{t}=2$ (representing an original claim at age 63 for someone who had some benefits withheld), $s s n_{t}=3$ (representing an original claim at age 64 for someone who had some benefits withheld), etc. With this structure we are able to separate, for example, 
whether someone is a 63 claimer, denoted by $s s_{t}=63$, or is really a 62 claimer who has accumulated one year of withheld benefits, represented here by $s s_{t}=63 n$. These two individuals will receive the same amount of benefits after the NRA, but their benefit would differ before the NRA, as in our previous example.

In addition to age, wealth, health, Social Security status, Benefit Adjustment status, and current income, the average indexed wage is a key variable in the dynamic model, serving two roles: (1) it acts as a measure of permanent income that serves as a convenient sufficient statistic for capturing serial correlation and predicting the evolution of annual wage earnings; and (2) it is key to accurately model the rules governing payment of the Social Security benefits. An individual's highest 35 years of earnings are averaged and the resulting Average Indexed Earnings (AIE) is denoted as $a w_{t}$. If there is less than 35 years of earnings when the person first becomes eligible for OASI, then the 5 lowest years of earnings are dropped and the remaining wages are averaged. Social Security usually reports the monthly equivalent or AIME. The PIA is the potential Social Security benefit rate for retiring at the NRA. It is a piece-wise linear, concave function of $a w_{t}$, whose value is denoted by pia $\left(a w_{t}\right)$.

In principle, one needs to keep as state variables the entire past earnings history. To avoid this, we follow Benítez-Silva and Heiland (2007) and approximate the evolution of average wages in a Markovian fashion; that is, period $t+1$ average wage, $a w_{t+1}$, is predicted using only age, $t$, current average wage, $a w_{t}$, and current period earnings, $y_{t}$. Within a log-normal regression model, we follow Benítez-Silva, Buchinsky, and Rust (2003 and 2006), such that the average wages take the form:

$$
\log \left(a w_{t+1}\right)=\gamma_{1}+\gamma_{2} \log \left(y_{t}\right)+\gamma_{3} \log \left(a w_{t}\right)+\gamma_{4} t+\gamma_{5} t^{2}+\varepsilon_{t} .
$$

The $R^{2}$ for this type of regression is very high, with an extremely small estimated standard error, resulting from the low variability of the $\left\{a w_{t}\right\}$ sequences. This is a key aspect of the model, given the important computational simplification that allows us to accurately model the Social Security rules in our DP model with a minimal number of state variables.

We then use the observed sequence of average wages as regressors to estimate the 
following log-normal regression model of an individual's annual earnings:

$$
\log \left(y_{t+1}\right)=\alpha_{1}+\alpha_{2} \log \left(a w_{t}\right)+\alpha_{3} t+\alpha_{4} t^{2}+\eta_{t} .
$$

This equation describes the evolution of earnings for full-time employment. Part-time workers are assumed to earn a pro-rata share of the full-time earnings level (that is, parttime earnings are $0.8 \cdot 800 / 2000$ of the full-time wage level given in equation (2)). The factor of 0.8 incorporates the assumption that the rate of pay working part time is $80 \%$ of the full-time rate. Using the history of earnings from the restricted HRS data set, we obtained very high $R^{2}$ using this methodology.

The advantage of using $a w_{t}$ instead of the actual Average Indexed Earnings is that $a w_{t}$ becomes a sufficient statistic for the person's earnings history. Thus, we need only keep track of $a w_{t}$, and update it recursively using the latest earnings according to (1), rather than having to keep track of the entire earnings history, in order to determine the 35 highest earnings years, which the AIE requires.

For the 1943-54 cohort the NRA is 66 and the PIA is permanently reduced after the NRA by an actuarial reduction factor of $\exp \left(-g_{1}(k-\operatorname{adjm})\right)$, where $k$ is the number of years prior to the NRA but after the ERA that the individual first starts receiving OASI benefits and adjm corrects for periods where no benefits were received, due to earnings above the Earnings test limit. Before the NRA, benefits are reduced by an actuarial reduction factor of $\exp \left(-g_{1} k\right)$. In the absence of adjustments to the ARFs, the actuarial reduction rate for the 1943 to 1954 cohort is $g_{1}=.0713$, which results in a reduced benefit of $75 \%$ of the PIA for an individual who first starts receiving OASI benefits at age 62, in the absence of any adjustments of the ARFs.

To increase the incentives to delay retirement, the 1983 Social Security reforms gradually increased the NRA from 65 to 67 and increased the delayed retirement credit (DRC). This is a permanent increase in the PIA by a factor of $\exp \left\{g_{2} l\right\}$, where $l$ denotes the number of years after the NRA that the individual delays receiving OASI benefits. The rate $g_{2}$ is being gradually increased over time. The relevant value for the 1943 to 1954 cohort is $g_{2}=0.0769$, which corresponds to an increase in $8 \%$ in benefits per year of delay after the NRA. The maximum value of $l$ is MRA - NRA, where MRA denotes a 
"maximum retirement age" (currently 70), beyond which further delays in retirement yield no further increases in PIA. As noted above, it is not optimal to delay applying for OASI benefits beyond the MRA, because due to mortality, further delays generally reduce the present value of OASI benefits the person will collect over their remaining lifetime.

We assume that the individual's utility is given by

$$
u_{t}(c, l, h, a g e)=\frac{c^{\gamma}-1}{\gamma}+\phi(\text { age }, h, a w) \log (l)-2 h,
$$

where $h$ denotes the health status and $\phi(a g e, h, a w)$ is a weight that can be interpreted as the relative disutility of work. We use the same specification for $\phi$ and the disutility from working as in Benítez-Silva, Buchinsky, and Rust (2006). The disutility of work increases with age, and is uniformly higher the worse one's health is. If an individual is in good health, the disutility of work increases much more gradually with age compared to the poor health, or disabled health, states. The disutility of work decreases with average wage. We postulate that high wage workers, especially highly educated professionals, have better working conditions than most lower wage blue collar workers, whose jobs are more likely to involve less pleasant, more repetitive, working conditions and a higher level of physical labor.

We assume that there are no time or financial costs involved in applying for OASI benefits.

The parameter $\gamma$ indexes the individual's level of risk aversion. As $\gamma \rightarrow 0$ the utility of consumption approaches $\log (c)$. We use $\gamma=-.37$, which corresponds to a moderate degree of risk aversion; that is, implied behavior that is slightly more risk averse than that implied by logarithmic preferences.

This benchmark model is closely related to the ones presented in Benítez-Silva and Heiland (2007), and Benítez-Silva et al. (2009), and does a good job at matching some of the most elusive evidence regarding individual behavior at older ages. As mentioned before this model improves upon those mentioned by also modeling employment uncertainty and unemployment insurance, and does an excellent job at matching the evidence on the claiming behavior in the United States. 
Table 3 below shows the proportion of retirement claiming by age predicted by the model compared to the actual data using the Statistical Supplement to the Social Security Bulletin in its 2007 edition, which uses 2006 data. We can easily see how well the model does in replicating the data, with only an over-prediction of claiming at age 63 compared with the Supplement.

Table 3. Actual vs. Simulated Retirement Claiming.

\begin{tabular}{|l|l|l|}
\hline Age & Actual (\%) & Simulated (\%) \\
\hline 62 & 53.8 & 52.93 \\
\hline 63 & 8.56 & 15.84 \\
\hline 64 & 10.4 & 11.16 \\
\hline 65 & 22.3 & 17.82 \\
\hline $66+$ & 2.7 & 2.22 \\
\hline
\end{tabular}

Of course, this fairly accurate prediction is accomplished with a host of assumptions, chief among them the fact that individuals know, understand, and optimally respond to the complex set of rules of the U.S. Social Security system. This assumption is clearly at odds with the evidence we presented in the previous section, unless we could argue that agents behave rationally and optimally because the cost of acquiring the information is too large compared with the gains from acquiring it.

The next step, and the key to this second part of our research, is to use this model to assess the consequences of setting up a different information structure, one in which individuals would not have full information about the retirement system. We then proceed to set up such a framework, while at the same time keeping all the other sources of uncertainty constant, and matching again the best we can the average claiming behavior in the data.

There are many possible informational structures we could set up, but not all of them are easy to incorporate in our framework. It is not clear which of these structures better reflects reality, and it might not be possible to actually decide over the possible 
informational structures, at the end of the day it is probably a good idea to perform a welfare analysis under a number of these structures to see if a pattern emerges. We have chosen a very simple sub-optimal information structure, one in which individuals choose to copy the people around them when deciding when to claim benefits. This means agents do not behave optimally, and do not take into account their state variables when making the decision, and instead they behave like the average person in the population, following the optimal distribution of claiming conditional on not having claimed before. This means for example, that when an individual reaches age 62, does not know what is optimal for him or her to do, but knows that around 52\% of those who reach that age and are eligible claim at that age, and that is what they do probabilistically to match that average. The actual implementation of this informational structure in the dynamic model is technically complex since a probabilistic set of actions is hard to model, and it forces as to solve the model under the assumption that individuals claim as early as possible when they reach an age without having claimed before, but only get the continuation value of having claimed following the empirical distribution of the optimal behavior.

In the simulations of the model it is a bit easier since we just compare probabilistic draws with the average claiming hazard implied by optimal behavior.

Notice that by behaving like the average person we will on average observe that regarding claiming the two alternative models will basically seem identical, but there will be welfare differences because under the new information structure individuals ignore some of their information and trust the people around them to decide what is optimal for them.

We then re-solve and re-simulate the model under this new structure in which individuals copy those around them instead of computing their optimal choice. Once we have re-solved the model we can perform a welfare calculation in which in this case we compute the willingness to pay of individuals in order to avoid moving from the optimal information structure to the new information structure. We know individuals would have to be compensated to move to the suboptimal informational structure, the question is by how much, by what proportion of their wealth.

Our initial findings indicate that the welfare improvement from having access to complete information vary by age, which could be expected, since the gains for certain 
individuals of a better informational structure many years into the future is small. On the other hand, for those close to retirement the gains are very large, and most of them benefit from the better structure.

We find that $95 \%$ of those who reach age 60 would have to be compensated with more than $50 \%$ of their wealth in order to move to the sub-optimal informational structure, which means they value the information tremendously. This is quite coherent since they are very close to retirement age, and whether they make the right decision or not has a large effect on welfare. However, only $28 \%$ of those who reach age 40 value the complete information structure, but those who do value it, do it as much as the 60 year old agent. The percentage of those who benefit from good information goes up to $32 \%$ at age 50, and again the welfare gain is very large for those who value it.

These results, while preliminary, are consistent with the surveys with respect to the effect of age, given that younger individuals are less likely to gain from the better information, and therefore it should not come as a surprise that they are less likely to acquire it. On the other hand, those who benefit from it at any age see a large welfare gain which indicates that policies directed at enhancing the Social Security literacy of individuals should pay off in terms of welfare gains in the population.

\section{Conclusions}

This paper is one of the first studies that we are aware of, which investigates the implications of people's knowledge of Social Security rules on their wealth, retirement outcomes, and welfare using a structural life-cycle model. The methodology outlined in this proposal allows us to go beyond documenting the extent of the knowledge within the population regarding the rules of the Social Security system. It allows us to provide, in a life-cycle framework, a formal characterization of the role of information on Social Security rules in the individual's decisions-making, the likely costs attached to acquiring it, and the welfare costs of not obtaining it.

In this version of the paper we have chosen a particular sub-optimal informational structure to compare with the full-information case, but many others are possible, and it is debatable which informational structure should be chosen to more accurately perform the 
welfare gains from informational investments. It seems to us that faced with this situation it would be ideal to show a range of welfare calculations depending on the informational assumptions we make. This is what we hope to do in future versions of this work.

We believe it is a natural extension of our work to consider how individuals learn about the incentive structures of the system. The survey results show that there is considerable learning among re-interviewers, which suggests that just by being asked individuals feel compelled to learn about the issue, which also suggests that considerable gains can be obtained with relatively small investments that float questions among the population. A more complex issue is the actual learning process, and the balancing of gains and costs underlying the decision to invest in informational improvements.

Finally, it is clear that given the pervasive lack of knowledge, and the large gains from additional information, especially for older individuals, we have to be very aware of the predictions of our models under the assumption of perfect information, especially regarding the consequences of policy changes assumed to be understood and followed rationally by individuals. Our framework can provide some guidance in assessing the robustness of policy recommendations to different informational structures. 


\section{References}

Benítez-Silva, H., Buchinsky, M., \& Rust, J. (2003). Dynamic structural models of retirement and disability. Manuscript, SUNY-Stony Brook, UCLA, and University of Maryland.

Benítez-Silva, H., Buchinsky, M., \& Rust, J. (2006). Induced entry effects of a \$1 for \$2 offset in SSDI benefits. Manuscript submitted for publication.

Benítez-Silva, H., Dwyer, D. S., Heiland, F., \& Sanderson, W. C. (2009). A dynamic model of retirement and Social Security reform expectations: A solution to the new early retirement puzzle. Manuscript submitted for publication. MRRC Working Paper No. 2006-134.

Benítez-Silva, H., \& Heiland, F. (2007). The Social Security Earnings Test and Work Incentives. Journal of Policy Analysis and Management, Vol. 26(3), 527-555.

Benjamin, D.J., Brown, S.A., \& Shapiro, J.M (2006). Who is Behavioral? Cognitive Ability and Anomalous Preferences. Manuscript.

Blau, D. (2008). Retirement and consumption in a life cycle model. Journal of Labor Economics, Vol. 26-1, 35-71.

Blinder, A. S., \& Krueger, A. B. (2004). What does the public know about economic policy, and how does it know it? Brookings Papers on Economic Activity, 1, 327-397.

Cao, H., \& Hill, D. H. (2005). Knowledge and preference in reporting financial information. Michigan Retirement Research Center Working Paper No. 2005-10.

Fagin, R. \& Halpern, J. (1988). Belief, awareness, and limited reasoning, Artificial Intelligence, 34, 39-76.

Feinberg, Y. (2004). Subjective reasoning - games with unawareness, mimeo, Stanford University.

Feinberg, Y. (2005). Games with incomplete awareness, mimeo, Stanford University.

French, E. (2005). The effects of health, wealth, an wages on labour supply and retirement Behaviour. Review of Economic Studies, 72, 395-427.

Gustman, A. L., \& Steinmeier, T. L. (2001). Imperfect knowledge, retirement and saving. NBER Working Paper No. w8406. Cambridge, MA: National Bureau of Economic Research.

Gustman, A. L., Steinmeier, T. L., \& Tabatabai, N. (2007). Imperfect knowledge of pension plan type. MRRC Working Paper. 
Heifetz, A., Meier, M. \& Schipper, B.C. (2006). Interactive unawareness, Journal of Economic Theory, 130, 78-94.

Heifetz, A., Meier, M. \& Schipper, B.C. (2007). Unawareness, beliefs, and games, mimeo, The University of California, Davis.

Li, J. (2006a). Information structures with unawareness, mimeo., University of Pennsylvania.

Li, J. (2006b). Dynamic games of complete information with unawareness, mimeo, University of Pennsylvania.

Lusardi, A., \& Mitchell, O.S. (2005). Financial Literacy and Planning: Implications for Retirement Wellbeing. MRRC Working Paper.

Lusardi, A., \& Mitchell, O.S. (2007). Planning and Financial Literacy Among US Households: New Evidence from the Rand Internet Panel. MRRC WP 2007-157.

Mastrobuoni, G. (2006). Do better-informed workers make better retirement choices? A test based on the Social Security Statement. Manuscript, Princeton University.

Mitchell, O. S. (1988). Worker knowledge of pension provisions. Journal of Labor Economics, 6(1), 21-39.

Modica, S. \& Rustichini, A. (1994). Awareness and partitional information structures, Theory and Decision, 37, 107-124.

Modica, S. \& Rustichini, A. (1999). Unawareness and partitional information structures, Games and Economic Behavior, 27, 265-298.

Rego, L. C. \& Halpern, J. (2007). Generalized solution concepts in games with possibly unaware players, mimeo, Federal University of Pernambuco.

Rust, J., \& Phelan, C. (1997). How Social Security and Medicare affect retirement behavior in a world of incomplete markets. Econometrica, 65(4), 781-831.

SSA-S (various years): Annual statistical supplement to the Social Security Bulletin. Available at http://www.ssa.gov/policy/docs/statcomps/supplement/

Starr-McCluer, M., \& Sundén, A. (1999). Workers' knowledge of their pension coverage: A reevaluation. Manuscript, Federal Reserve Board of Governors.

Stevens, A-H., \& Chan, S. (2005). What you don’t know can’t help you: Pension Knowledge and Retirement Decision Making. Manuscript.

Van der Klaauw, W., \& K.I. Wolpin (2008): "Social Security, Pensions and the Savings and Retirement Behavior of Low-Income Households,” Journal of Econometrics, 145, 21-42. 